\title{
Exploration of Hybrid FSO/RF Availabilities in Optical Wireless System
}

\author{
Ajay Sharma, Rajendra Singh Kaler, Shamimul Qamar, Himanshu Monga, Navneet Sharma
}

\begin{abstract}
In this paper a more practical solution has investigate by extend the range of availability through FSO back-up link with a radio frequency $(\mathrm{RF})$ link of lower data rate. This paper investigate the technical advantages of integrating FSO and $R F$ communication systems to get availability of $99.999 \%$ to expand a new system called hybrid/dual RF/FSOF system. Analysis shows that a consequences of rain and fog have an effect on the $R F$ and FSO links severally however not at the same time and barely occur at the same time to grant the choice to build up new hybrid FSO/RF system.
\end{abstract}

Index Terms: Radio Frequency, Free Space Optics, Hybrid RF/FSO, Visibility, Availability

\section{INTRODUCTION}

The Free Space Optical Communication approaching like a wireless, large-bandwidth access technological tool. Since Free Space Optics has lesser cost and considerably less fitting time, FSO is currently adopted an alternate option in place of fiber for limited distances.

Communication through free space by LASER is predictable to participate in $5 \mathrm{G}$ wireless networks. Free space optics (FSO) links provide as potential substitute to the conventional fiber optic cables used for backup links due to the easiness of employment, quick arrangement time, and small repair cost [1], [2]. The negative aspect of FSO is that it needs a clear line-of-sight (LOS) path and atmospheric turbulence has influenced the propagation of light signal [3].

The progress of wireless communications standards in $4^{\text {th }}$ generation has witness latest quick advancement in technologies of Communication System. The increased demand within the business marketplace to use unrestricted speedy and wireless broadband access has resulted into rigorous overcrowding of the RF frequency spectrum [4].

Complement the present wireless RF system, optical wireless is turn into a capable wideband wireless access contestant to solve present within a mile issue due to its better quality of FSO technique, which includes licensing free need for its

Revised Manuscript Received on July 5, 2019.

Ajay Sharma, Electronics \& Communication Engineering Department, JIMS Engineering Management Technical Campus, Greater Noida, India,

R.S Kaler, Electronics \& Communication Engineering Department, Thapar Institute of Engineering \& Technology, Patiala, India.

Shamimul Qamar, Computer Network \& Communication Engineering Department, College of Computer Science, King Khalid University, Abha, Saudi Arabia.

Himanshu Monga, Electronics \& Communication Engineering Department, Jawahar Lal Nehru Govt. Engineering College, Mandi, India.

Navneet Sharma, Electronics \& Communication Engineering Department, ABES Engineering College, Ghaziabad, India. operation, lowered interfering, high protection, cost-efficiency and ease of system plan [5].

Optical wireless still as one of the least used broadband technology, by knowing the fact that its incredible prospective in solving the issue of last mile, because of its competence of achieve capacity equivalent to optical fibre cable with least deployment cost and rapid installation period [6-7]. The extensive use of optical wireless systems is rigorously limited by the adverse effects of the atmospheric conditions [8-10], which is highly changeable and irregular or random due to climate dependence. This in turn causes major optical power degradation and reduced link range, thus falling short of the required $99.999 \%$ carrier availability. Kim and Korevaar have evaluated the impact of attenuation on the range of communication link and the availability intended for carrier and enterprise class FSO systems throughout the historical weather data and link budget analysis [12].

Relevant research studies starting the most current years shown that the channel diversity methods present a more feasible and an efficient mitigation technique in highly bad weather conditions. The mainly well-known option is to utilize lower data-rate RF system along with the FSO system to get link range extension at the same time as maintain the required link availability during the times when the main FSO link is low [11-13]. The approach to build up such hybrid/dual RF/FSO systems which based on experimental and theoretical validations that replicate the association among these two technology options, because rain and fog severely affect the RF and FSO system respectively and rarely occur simultaneously $[6,9]$.

\section{CARRIER AND ENTERPRISE CLASS FSO LINK}

The visibility record is obtainable for almost all airports in the globe $[14,15]$. Carrier access applications require high availability as compare to enterprise applications. The standard carrier-class required $99.999 \%$ availability.

The leading measured attenuation in fog condition is 350 $\mathrm{dB} / \mathrm{km}$ [15]. As attenuation due to fog is not depend on wavelength, the similar utmost attenuation come $350 \mathrm{~dB} / \mathrm{km}$, when implement to $850 \mathrm{~nm}$ and $1550 \mathrm{~nm}$ wavelength based FSO system [10, 16].

Published By: 
Maximum FSO range in $350 \mathrm{~dB} / \mathrm{km}$ fog attenuation has between $110 \mathrm{~m}$ to $140 \mathrm{~m}$. Hence, $99.999 \%$ availability is attainable by FSO only at previous mentioned short distances [17].

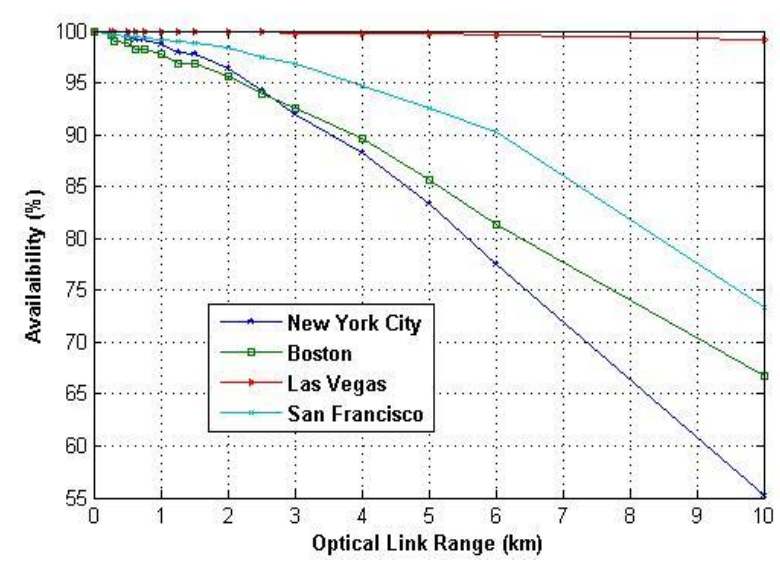

Fig. 1. Optical Link Range vs. Availability in FSO System

\section{RF BACK-UP MAXIMIZING LINK AVAILABILITY IN ALL WEATHER CONDITIONS}

By rising the power transmitted or by large aperture receiver through automatic tracking systems cannot considerably increase FSO quality in bad weather conditions. Then it is required to implement a RF back-up, which could not be limited by bad weather conditions like fog. As FSO is the license-free then RF as a back-up must also be a license free structure. Carrier-class availability of $99.999 \%$ can be maintained with this FSO/RF hybrid system at longer ranges as compared with FSO-only link range [9].

This system utilizes the internationally unlicensed $2.4 \mathrm{GHz}$ bandwidth along with FSO system. This system has a free space optical link that has connectivity of fast Ethernet as the main link and Ethernet RF as the secondary link. This dual system operates in almost all weather conditions, like heavy rain, fog and snow at almost $99.999 \%$ link availability. This system is licensing free and easy in installation.

\section{MODEL OF FSO AND RF CHANNEL}

Atmospheric loss is mainly due to the factors like absorption, scattering and attenuation. Mathematically it can be representing by Beers-Lambert law [18].

$$
\beta=\mathrm{e}^{-\alpha \mathrm{L}}
$$

Where $\alpha$ denotes an attenuation coefficient which depend upon atmospheric condition and $\mathrm{L}$ is the distance of propagation. For adverse atmospheric conditions, $\alpha$ has evaluated through visibility records by model of Kim [10].

$\alpha=\frac{3.91}{\mathrm{~V}}\left(\frac{\lambda_{1}}{550}\right)^{-\mathrm{q}}$

Where ' $\mathrm{V}$ ' denote visibility in $\mathrm{km}$, ' $\lambda_{1}$ ' represents laser wavelength in $\mathrm{nm}$, and ' $\mathrm{q}$ ' is particle size distribution. The irradiance fluctuations also called scintillation due to atmospheric turbulence in the weak turbulence system comes due to indiscriminate change in the refractive index of free space alongside with the transmission path. This scintillation is comes from log-normal fading model. The probability density function of this intensity (I) due to fluctuations in turbulent atmosphere given by [4].

$\mathrm{P}(\mathrm{I})=\frac{1}{\mathrm{I} \sigma_{1}(\mathrm{D}) \sqrt{2 \pi}} \exp \left\{\frac{\left[\ln \left(\frac{\mathrm{I}}{\mathrm{I}}\right)+\frac{1}{2} \sigma_{1}^{2}(\mathrm{D})\right]^{2}}{2 \sigma_{1}^{2}(\mathrm{D})}\right\}, \mathrm{I}>0$

Where $\sigma_{1}^{2}(\mathrm{D}) i \mathrm{~s}$ index of scintillation and $\langle\mathrm{I}\rangle$ is the mean intensity.

The scintillation index $\sigma_{1}{ }^{2}$ (D) can be determined from the below equation [18]

$\sigma_{1}^{2}(\mathrm{D})=\exp \left[\frac{0.49 \chi^{2}}{\left(1+0.18 \mathrm{~d}^{2}+0.56 \chi^{12 / 5}\right)^{7 / 6}}+\frac{0.51 \chi^{2}\left(1+0.69 \chi^{12 / 5}\right)^{-5 / 6}}{1+0.90 \mathrm{~d}^{2}+0.62 \mathrm{~d}^{2} \chi^{12 / 5}}\right]-1$

Where,

$$
\chi^{2}=0.492\left(\frac{2 \pi}{\lambda_{1}}\right)^{7 / 6} C_{n}^{2} L^{1 / 6} \quad \& \quad d=\sqrt{\frac{2 \pi D^{2}}{4 \lambda_{1} L}}
$$

Where $\chi^{2}$ is the Rytov variance for spherical wave and D is receiver aperture represent. $C_{n}^{2}$ denotes the refractive-index structure parameter which represents the atmospheric turbulence strength. In the existence of turbulence, the signal to noise ratio (SNR) is a fluctuating or instantaneous term, so implying that the average (mean) value is required to provide a quantitative measure of the overall system performance. The mean signal to noise ratio $\left(\mathrm{SNR}_{1}\right)$ can be represented as [4]

$$
\mathrm{SNR}_{1}=\frac{\mathrm{SNR}_{0}}{\sqrt{\frac{\mathrm{P}_{\mathrm{S} 0}}{\mathrm{P}_{\mathrm{S}}}+\sigma_{\mathrm{I}}^{2}(\mathrm{D}) \mathrm{SNR}_{0}^{2}}}
$$

Where $\mathrm{SNR}_{0}$ represent Signal to Noise ratio in the non-turbulence condition, power of signal denotes by $\mathrm{P}_{\mathrm{SO}}$ in negligible atmospheric effects, $\left\langle P_{s}\right\rangle$ is the mean signal power at input and $\sigma_{1}^{2}(\mathrm{D})$ denotes scintillation index.

A RF link working at an unlicensed carrier frequency by using amplitude shift keying (ASK) is regarded as a subsidiary link to the FSO link [19]. The overall gain $\mathrm{G}_{\mathrm{RF}}$ of the RF link can be modeled as [20]

$\mathrm{G}_{\mathrm{RF}}[\mathrm{dB}]=\mathrm{G}_{\mathrm{RX}}+\mathrm{G}_{\mathrm{TX}}-20 \log _{10}\left(\frac{4 \pi \mathrm{L}}{\lambda_{2}}\right)-\alpha_{\text {oxy }} \mathrm{L}-\alpha_{\text {rain }} \mathrm{L}$

Where $\mathrm{G}_{\mathrm{RX}}$ and $\mathrm{G}_{\mathrm{TX}}$ are the receiver and transmitter antenna gain respectively, $\lambda_{2}$ represent the wavelength of RF System, $\alpha_{\text {rain }} \& \alpha_{\text {oxy }}$ are attenuation due to rain and oxygen absorption in $\mathrm{dB} / \mathrm{km}$ correspondingly.

The noise variance of RF $\sigma_{R F}^{2}$ is gives as

$\sigma_{R F}^{2}(\mathrm{~dB})=\mathrm{BN}_{0}+\mathrm{N}_{\mathrm{F}}$

Where RF bandwidth is $\mathrm{B}, \mathrm{N}_{0}$ is the spectral density noise power in $\mathrm{dBm} / \mathrm{MHz}$ and $\mathrm{N}_{\mathrm{F}}$ is the receiver noise figure, so the SNR of RF link can be calculated as follows

$\mathrm{SNR}_{2}=\frac{\mathrm{P}_{\mathrm{RF}} \mathrm{G}_{\mathrm{RF}}}{\sigma_{\mathrm{RF}}^{2}}$ 
Figure 2 illustrates the SNR performance of RF and FSO links for the link distance L for clear air, heavy rain \& heavy fog conditions. The weather conditions are characterized by various parameters, which includes $\mathrm{V}$ (visibility), $\alpha$ (the attenuation), caused by rain and $C_{n}^{2}$ (turbulence strength).

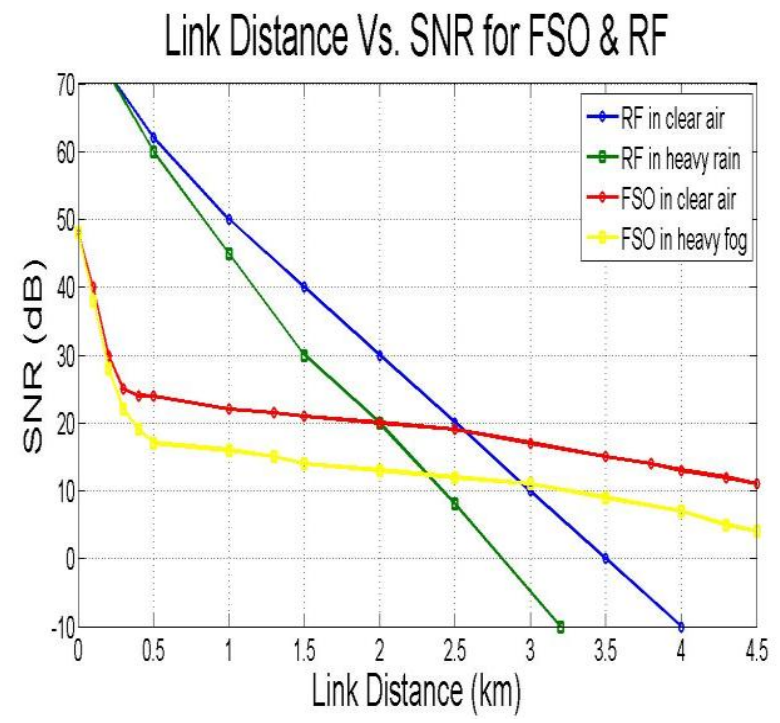

Fig. 2. Link distance Vs. SNR for FSO and RF

From the result, it is clear that system of FSO is able of maintain connectivity in clear air and moderate rain conditions. This in turn reveals the inherent advantage of the free space optics link to use in a speedy communication system underneath undesirable rain effect. However, the FSO system encounters extreme performance degradation under foggy weather conditions, in which the link crash occurs at $\sim 2.5 \mathrm{~km}$ in the presence of fog, while the RF link still maintains an SNR of $20 \mathrm{~dB}$.

In particular, observation shows that the FSO link could only establish a communication range of $500 \mathrm{~m}$ for an SNR of 18 $\mathrm{dB}$ under the heavy fog condition, while the RF link outperforms with a corresponding link distance of $\sim 2.6 \mathrm{~km}$. therefore, the important benefit of both RF and FSO systems is to back each other underneath the effects of fog and rain respectively.

\section{CONCLUSION}

This manuscript shows that the availability of FSO/RF hybrid system can be improved and give $99.999 \%$ availability as compared with FSO-solitary system. Due to the availability of this hybrid/dual RF/FSO scheme, a great extent metro area is now accessible for the users. Study shows the relationship between these technology options, whereby rain and fog drastically affect the RF and FSO links respectively and rarely occur concurrently. Underneath intense fog conditions, the radio frequency (RF) system is able to be used as a complementary link to attain high expansion in the link range for a particular signal to noise ratio (SNR). Therefore, hybrid/dual RF/FSO system is a viable means to minimize performance deprivation due to poor weather effects experienced by traditional FSO systems.

\section{REFERENCES}

1. J. M. Kahn, D. A. Miller, "Communications expands its space", Nature Photon., vol. 11, no. 1, pp. 5-8, Jan. 2017.

2. M. Alzenad, M. Z. Shakir, H. Yanikomeroglu, M. S. Alouini, "FSO-based vertical backhaul/fronthaul framework for $5 \mathrm{G}+$ wireless networks", IEEE Commun. Mag., vol. 56, no. 1, pp. 218-224, Jan 2018 .

3. I.Sousa, M. P. Queluz, A. Rodrigues, "An efficient visibility prediction framework for free-space optical systems", Wireless Pers. Commun. vol. 96, no. 3, pp. 3483-3498, Oct. 2017.

4. A. K. Majumder and J. C. Ricklin, "Free-space laser communications", New York, NY: Springer, 2008.

5. A. Mahdy and J. S. Deogun, "Wireless optical communications: a survey", Proceedings of IEEE Wireless Communications and Networking Conference (WCNC), 2004, Atlanta, USA, pp. 2399-2404.

6. A. AbdulHussein, A. Oka, T. T. Nguyen and L. Lampe, "Rateless coding for hybrid free-space optical and radio-frequency communication", IEEE Trans. Wireless Commun., vol. 9, pp. 907913, 2010.

7. S. Vangala and H. Pishro-Nik, "A highly reliable FSO/RF communication system using efficient codes", in Proc. IEEE Global Telecommunications Conference (GLOBECOM), 2007, Washington DC, USA, pp. 2232-2236.

8. S. Bloom and W. Hartley, "The last-mile solution: hybrid FSO radio," in Whitepaper, AirFiber Inc., May 2002.

9. I. I. Kim and E. Korevaar, "Availability of free space optics (FSO) and hybrid FSO/RF systems", in Proc. SPIE, Optical Wireless Communications IV, 2001, Denver, CO, USA, vol. 4530, pp. 84-95.

10. I. I. Kim, B. McArthur, and E. Korevaar, "Comparison of laser beam propagation at $785 \mathrm{~nm}$ and $1550 \mathrm{~nm}$ in fog and haze for optical wireless communications", Proc. SPIE, 2001, vol. 4214, pp. 26- 37.

11. B. He and R. Schober, "Bit-interleaved coded modulation for hybrid RF/FSO systems", IEEE Trans. Commun., vol. 57, no. 12, pp. 3753-3763, 2009.

12. H. Tapse and D. K. Borah, "Hybrid optical/RF channels: characterization and performance study using low density parity check codes”, IEEE Trans. Commun.,vol. 57, no. 11, pp. 3288- 3297, 2009.

13. W. Zhang, S. Hranilovic and C. Shi, "Soft-switching hybrid FSO/RF links using short-length Raptor codes: design and implementation", IEEE J. Sel. Areas Comm., vol. 27, pp. 1698-1708, 2009.

14. I. I. Kim, R. Stieger, J. Koontz, C. Moursund, M. Barclay, P. Adhikari, J. Schuster, and E. Korevaar, "Wireless optical transmission of Fast Ethernet, FDDI, ATM, and ESCON protocol data using the TerraLink laser communication system," Opt. Eng., vol. 37, pp. 3143-3155, 1998.

15. International station meteorological climate summary. Ver. 4.0, Federal Climate Complex Asheville, 1996

16. T. H. Carbonneau and D. R. Wisely, "Opportunities and challenges for optical wireless; the competitive advantage of free space telecommunications links in today's crowded marketplace," Wireless Technologies and Systems: Millimeter Wave and Optical, Proc. SPIE, 1997, 3232, pp. 119-128

17. I. I. Kim, R. Stieger, J. Koontz, C. Moursund, M. Barclay, P. Adhikari, J. Schuster, and E. Korevaar, "Wireless optical transmission of Fast Ethernet, FDDI, ATM, and ESCON protocol data using the TerraLink laser communication system," Opt. Eng., vol. 37, pp. 3143- 3155, 1998.

18. L. C. Andrews and R. L. Philips, "Laser beam propagation through random media", Washington, DC: SPIE, 2005

19. "AirebeamTM G60 Series datasheet", http://www.lightpointe.com/downloads/datasheets/Airebeam_G60.pd f [online], last accessed: Apr. 18, 2011.

20. J. Schothier, "WP3-study: the $60 \mathrm{GHz}$ channel and its modeling," Tech. Report, IST-2001-32686 Broadway, 2001. 


\section{AUTHORS PROFILE}

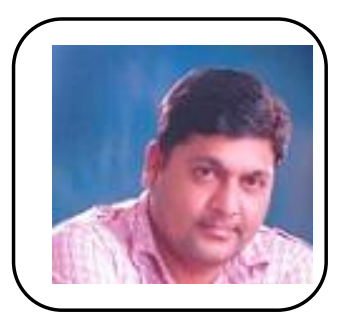

Dr.Ajay Sharma was born in Aligarh (U.P), India. Ajay Sharma did B.E in Electronics \& Communication Engineering from Barktullah University Bhopal, M.P, India in 2000, M.E in Microwave \& Radar Engineering from Dr.B.R. Ambedkar University, Agra, U.P, India in 2006 \& PhD in Optical wireless from THAPAR University Patiala, Punjab, India.He published many research papers listed in SCI including IEEE Journal. His research interests are optical wireless, free space optical communication \& Microwave Engineering. Dr. Sharma is student member of IEEE \& SPIE societies. He has 18 years of academic experience.

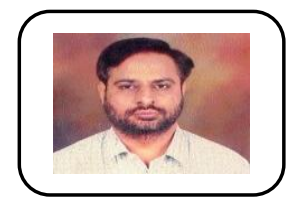

Dr.R.S Kaler did B.Tech. in Electronics and communication Engineering with Distinction from Guru Nanak Dev University, Amritsar, Punjab, India in 1990, M.E. in Electronics and Communication Engineering from Panjab University, Chandigarh, India 1995, Ph.D. in Electronics and Communication Engineering from Department of Electronics and Communication Engineering, Sant longowal Institute of Engineering and Technology (PTU), Longowal,Sangrur, Punjab, India in 2002. Presently working as Senior Professor \& Dean (Resource Planning \& Generation) in Department of Electronics and Communication Engineering, Thapar University, Patiala-147004, Punjab, India

His total research publications are around 200 in which publication in International Journals (SCI listed) are 150 and above.He published two books on Digital signal Processing \& Microprocessors and Microcontrollers. His Research areas are Fiber Optics communications, Optical Networks, Communication Systems, and Wireless Network.

$\mathrm{He}$ is a member of IEEE, SPIE and He has been a reviewer for journals \& conferences and acts as member of technical committees and chairperson on conferences

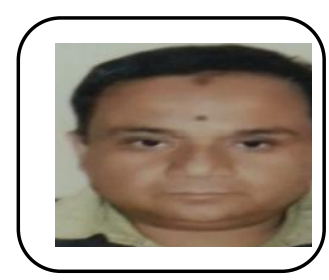

Dr. Shamimul Qamar, has been recognized as an eminent scholar in the field of Electronics \& Computer Engg.. He had done his B.Tech from MMMEC Gorakhpur, M.Tech from AMU, Aligarh and earned his Ph.D. degree from IIT Roorkee with highly honorable grade. Prof. Qamar has a wide teaching experience in various Engineering colleges. He has research interests in Communication \& Computer network, Computer Networks, Multimedia applications, Internet applications, Satellite network, DSP, Image Processing. He has published several research papers in reputed national/international Journals and conference. He served as Consultant in Jackson state university, USA. He is a reviewer of IJCSIS, USA. He has written some text books and chapters in the field of Electronics \& Computer Engineering. He is also a technical programme committee member in international mobility conference, Singapore.

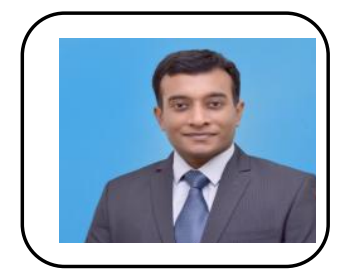

Navneet is having an excellent academic record, he studied his Bachelors in Engineering from Prestigious Delhi College of Engineering(Now, Delhi Technological University, New Delhi, in the field of Electronics and Communication Engineering, He did Masters in Technology fromDr. Abdul Kalam Technical University, Lucknow. Currently he is pursuing his $\mathrm{PhD}$ from IIT(ISM) Dhanbad in the field of Microwave Engineering, where his specialization is Indirect Holography through Phaseless Characterization. Navneet Sharma has published his research in various National and International Scopes Indexed Journals and also attended and presented papers in scores of national and international conferences. His research includes topics from Antenna, Microwave and optical Communication. His work on Capacity enhancement of CDMA is very well cited and appreciated. 